\title{
Markets for Inventors: \\ Examining Mobility Patterns of Engineers in the Semiconductor \\ Industry*
}

\author{
Neus Palomeras \\ Universitat Pompeu Fabra, Barcelona, Spain \\ $\&$ \\ Katolieke Universiteit Leuven, Leuven, Belgium
}

Preliminary Version

February 2004

\begin{abstract}
It is well known that the movement of people between organizations and regions results in knowledge diffusion, either in the form of internalized knowledge transfer or spillovers. In this paper, we attempt to highlight the drivers of mobility of researchers between firms in the electronics industry. The research in this industry is characterized by being patent-intensive and cumulative in nature, fact that anticipates that learning from the competitors is a key factor for the entrants on the industry or in a sub field. Our aim is to highlight: $i$ ) which type of knowledge outside firms want to get access to and ii) which the characteristics of the inventor's work may signal whether he possesses this type of knowledge or/and his ability to transfer it. Examining the inventors' moves from the big player in the industry, IBM, towards competing firms, we find that: $i$ ) their patents significantly differ from patents by no-movers and $i$ i) moves depend on the quality of the inventor's work, his experience in the industry and the firm and the number of coinventors he has worked with.
\end{abstract}

\footnotetext{
* I wish to specially thank Bruno Cassiman, my thesis director for his encouragement and suggestions.
} 


\section{Introduction}

It is well known that knowledge that sustains $R \& D$ activities at innovative firms can be either developed internally or acquired externally. If they consider external sourcing, they can concur to two different types of markets. They can acquire the rights to use some technology developed by a competitor in the market for technology or, alternatively, they can concur to the labor market, where they can hire the researchers responsible for the development of the knowledge of interest. The choice will depend on both the nature of the knowledge that the firm is interested in and its ability to absorb it.

In this paper, we pay attention to this particular way of moving ideas across firm boundaries. Indeed, labor mobility is a driver of technology transfer between firms. It has been for long suggested that labor mobility, especially of engineers, eroded the difference between technological levels of firms (Gilfillan, 1935). However, this topic has not attracted the attention of researchers until nowadays. One of the main reasons is the difficulty to track the change of the labor force among firms and to evaluate the impact on the hiring firms. Therefore, only some descriptive studies suggested that mobile people transfer knowledge between firms (Malecki, 1998; Hanson, 1982; Saxenian, 1990; Rogers and Larsen, 1984). Based on qualitative data obtained from surveys, some researchers analyzed the impact of the incorporation in firms of different technical and managerial employees (Ettlie, 1985; Boeker, 1997).

However, the most important stream of research around mobility issues of researchers has been linked to the spillovers it generates (Geroski, 1995; Jaffe et al, 1993; Agrawal et al, 2003), that Moen (2000) consider that, at least to some extent, are internalized by the workers. Nevertheless, much of this research would not have been possible without the recent possibility to codify and work with extensive datasets of patent data. This fact made possible to deepen the analysis of mobility of researchers and engineers, who possess the know-how relevant at innovative firms. Patents allow tracking the mobility of inventors -by their changes of affiliation- as well as the impact of the move in the hiring 
firm -through patent citations between the pair of firms involved-. In fact, most of the work on externalities mentioned previously is based on the analysis of patent citations as a proxy for the spillovers generated. Recently, another stream of research arose, focusing or the consequences of mobility on the hiring firms (Almeida and Kogut, 1999, Rosenkopf and Almeida, 2003 and Song et al., 2003) in the semiconductor industry or on the characteristics of the moving inventors in the biotech industry (Zucker et al., 2002), that relies on data of publications.

In this paper, I use as well patent data to track the mobility of engineers in the semiconductor industry. In particular, I restrict to a sample of engineers working at IBM and analyze their moves towards competing firms. I use the patent data to characterize the type of knowledge that outside firms want to get access to by hiring engineers working at IBM as well as the type of inventors they rely upon to transfer it. Findings support the idea that hiring seeks for learning some knowledge that is actually differentiated. The determinants of the likelihood of an inventor to move are not as related to the characteristics of the knowledge he possesses but at his/her productivity in qualitative terms, the extent to that he co-invents and his experience in the sector and firm.

\section{Literature Review}

The recent stream of literature on inventor's mobility has explored two types of moves: between firms -in the electronics case- and from the university to a firm -in the biotech case-. As well, they examine two different dimensions of the mobility, namely, i) the relative characteristics of the firm pairs and its consequences for the technology transfer and ii) the characteristics of the researchers on the likelihood of leaving.

Almeida and Kogut (1999) show that engineers'mobility is geographically bounded and as a consequence, the knowledge remains also geographically localized. Rosenkopf and Almeida (2003) emphasize also this localization effect but suggest that mobility is equally effective in terms of transferring knowledge independently of whether the move 
is intra or inter regional. However, they find that technological distance does affect positively the absorption of technology transfer. Song et al (2003) also find that the transfer of knowledge is more valuable when the engineer' skills are distant from the hiring firm's core. Mowery et al (1998) suggest as well that mobility is especially useful when the two firms do not technologically overlap. This argument has probably to do with the difficulty to codify and transmit knowledge across contexts, which make the acquisition of blueprints quite inefficient. Apart from that, it is quite obvious that the flow of information that can be transferred from outside is quantitatively greater than in similar settings. However, the actual absorptive capacity of the firm is relatively smaller than if the two firms are close-by in the technological space (Lane \& Lubatkin, 1998). In this case, the know-how brought from outside will be relatively marginal in quantitative terms but qualitatively important.

There is no much evidence on the type of firms involved in the market for hiring talent in terms of the relative experience of firms. Song et al (2003), in their analysis of the mobility of engineers between US and non-US firms give us some clue in that respect. They suggest that their results can be interpreted as evidence that both firms with and without established technological trajectories hire outside engineers, but with different aims. The formers are just interested in having high human capital and if they can find it in the competitor's labor force, they will hire them. On the contrary, the latters are interested in competitor's knowledge as a source of know-how. Rosenkopf and Almeida (2003) work with a sample of startups in the semiconductors that use mobility and alliances to absorb knowledge from incumbent firms. Zucker et al (2002) suggest that an important source of know-how for firms that want to commercialize breakthrough discoveries are university researchers. Moen (2000) finds that technical workers in the Norwegian machinery and equipment industry tend to move between firms with similar R\&D intensity.

Literature, however, has not paid attention to the characteristics of the moving researchers, except for Zucker et al (2002), who undertake this question in a universityfirm setting. They find that the quality of the researcher, the commercial potential of his 
inventions and his social network are significant determinants for his involvement in commercial applications of biotechnology -they also contemplate the role of entrepreneurship, i.e. researchers that leave to build a new firm.

There are a lot of questions still unanswered. In this paper, we focus in the just mentioned characteristics of the moving researchers from firm to firm. The hiring firm should not only consider which firm among its competitors has the knowledge it is interested in but also which among their scientists is the most able to transfer it.

In this paper, we examine the moves of engineers between firms from the perspective of the characteristics of the engineers' work, which we assume is the reason competitors are interested in them. This will allow us to determine what type of know-how do firms actually look for (or can get access to) when they hire external scientists as well as the probability of an engineer of the firm quitting.

\section{Motivation}

As Pavitt (1983) mentions it, "only about $10 \%$ of the innovations are new to the world". That is, the majority of the so-called innovations are not such but a recombination of existing knowledge. This simple fact tells us a lot about the importance of the engineers' mobility process. External ideas can be critical for the innovative process of an established firm. In fact, some recent literature suggests that external and internal knowledge are complementary. Silicon Valley is the example par excellence of the positive effects of labor mobility on highly innovative firms. On the one hand, with every new hiring firms are subject to new ideas that can recombine with the existing knowledge at the firm. On the other hand, the existence of a labor market in a geographical region keeps the engineers highly motivated because they know they can appropriate at least part of their investment in the creation of know-how by leaving the firm. Moreover, they know they are not tied to the ideas of their employers but they can move to other firms where they can exploit their ideas. 
Apart from being complementary to internal knowledge, external know-how is especially important by entrants in a sector such as electronics, where innovation is cumulative. In this case, learning-by-hiring can be the most efficient method to learn about the current state of the technique. Therefore, in an innovative sector, hiring engineers working at competing firms is a mechanism for both incumbents and entrants to keep up with the innovative pace of the industry. Engineers are increasingly mobile: according to the US Labor Bureau, the median years of tenure of engineers was as of 2002 of 4.8 years compared with 6.3 years in 1983 .

Understanding the mobility of inventors is important also from the perspective of the firms that employ them and face the risk of them leaving. Knowing which type of inventors are more likely to leave may help in the design of more efficient contracts or incentive schemes that help to retain them or, at least, to minimize the impact of their quits.

Therefore, understanding mobility flows in an innovative industry can help us to understand knowledge flows. A comprehensive analysis should take into account the different perspectives of the actors involved, i.e. the hiring firms, the inventors that change firm and the current firms that employ the inventors. Which kind of firms seek outside knowledge, which kind of firms act as a source of knowledge and which inventors are more likely to move are key questions to understand the learning-by-hiring process.

\section{The probability of move}

As we just mentioned, the analysis of the mobility of an inventor between firms must take into account the incentives of the hiring firm, the current firm and the own inventor. A move is the result of: the interest in the inventor by another firm, the lower interest in the inventor by his current firm and the willingness of the inventor to move. Therefore, the probability to observe a move is the sum of the probability to receive an outside offer 
plus the probability of not receiving a higher counteroffer by his current firm plus the probability that he actually wants to move.

\subsection{The probability of receiving an outside offer}

As mentioned, external firms hire in order to learn and increase their innovative capabilities. Therefore, they will seek for inventors from whom they could actually learn, i.e. inventors with a high stock of knowledge and the ability to transfer it to a new setting -firm or field-. As Song et al.(2003) point out, the engineers with higher abilities are more likely " to have more knowledge to transfer than those with weaker abilities". High research abilities would reflect in various aspects of the inventor's characteristics, but especially in the quantity and quality of his accumulated know-how. Transfer abilities are not that easy to anticipate, but some characteristics of the inventor's work can signal his ability of interdisciplinary work.

The accumulated know-how of an inventor increases as his career progresses, i.e. as he spends more years doing research in the firm (the tenure) and in the sector (the experience). For the same years at work, the productivity of an engineer reflect his ability to innovate and the stock of knowledge that he accumulates. A simple measure of the productivity is the quantity of research outcomes in a period of time. Alternatively, it can be measured taking into account the quality of these outcomes. In R\&D activities, the qualitative measure is likely to be far more important than the number of outcomes (Zucker et al, 2002). However, in a patent-intensive sector such as the semiconductors both aspects could be quite important. It is important to take into account the individual contribution of the individual in the research outcomes, since many of the research in the electronics industry is performed in teams. The more co-inventors in a team, the less the individual contribution in terms of effort and value.

Apart from the stock of know-how, there are some characteristics of the inventor's knowledge that are likely to be of particular interest for prospective employers. For instance, external firms will particularly seek for the know-how associated to highly 
valuable innovations. Therefore, the extent to which the inventor's knowledge is embodied in economically valuable inventions is positively related to the interest of outside firms in his work. The quality of the work has been proved a proxy for the economical value of the underlying innovation (Harhoff et al, 1999). Another dimension of value is related to the scarcity of the knowledge that possess the inventor. Everything else equal, an inventor with a more unique know-how inside the firm will have a higher probability to receive an external offer. Looking at the value of an invention from another point of view, namely, its suitability to be actually implemented by a firm, the more cumulative an invention is, as opposite to radical, the more likely it is to be implemented by an established firm (Shane, 2000). Therefore, the inventor's ability to innovate in a cumulative, and therefore, useful way for an established firm, may increase the likelihood that he receives an offer.

It is likely that the hiring firm is interested in the engineers working at the core of their current firm. Put in a different way, a firm wants to learn about a particular type of knowhow will try to get access to it from a firm that is among the best at this knowledge which probably will have this activity in its core-. Song et al (2003) points out that the useful knowledge for hiring firms is likely to be the one stemming from the core knowledge of the previous firm.

Song et al (2003) also suggest that firms also value the ability to apply it in different contexts. This ability is likely to be stronger the more spread (i.e. interdisciplinary) the knowledge base of the inventor is across fields of technology. As well, a firm interested in a certain knowledge but distant in the technological space from its source is likely to rely on an inventor who possess more generic know-how. The more generic it is, the more likely it could be applied to different technological fields.

\subsection{The probability of the offer not being matched}

Of particular interest is the "auction" of the worker between the two firms. Labor literature dealing with mobility issues model this auction (REF). The basic argument 
behind it is that the expected marginal productivity of the worker in the new firm is greater than the marginal productivity in the current firm. The reason is that in the former case there is a better match between the human capital of the worker and the productivity function of the firm than in the latter case. We will assume that this is indeed the reason why firms "let leave" their inventors: they can not match the offer done by the other firm because the marginal productivity they can obtain of the employee is lower.

Therefore, not all of the inventors that receive an outside offer will be actually leaving. If we predict that outside offers depend on a vector of inventor's characteristics, we have to take into account too how these characteristics are likely to be valued by the current employer and, therefore, what is the probability that the current firm matches the offer done by the outside firm and retains the employee.

It is likely that the engineers with high human capital, more valuable knowledge and working at the firm's core are the most valued by their current employers as well. Therefore, the engineers with these characteristics are the most likely to receive outside offers but also to be retained by their current employers. In such cases, we would expect that the probability to move is represented by an inverse U-shaped curve-form with respect the mentioned vector of variables. This form arises from the sum of the probability of getting an offer from outside -increasing with the human capital of the inventor- plus the probability of not getting a counteroffer from the current employer decreasing with the human capital of the inventor-.

The fit of the inventor's research in the current firm's R\&D strategy may play an important role in the decision of his current firm to retain him. If the engineer works in a research stream to which the firm is actually not interested in, it is likely it does not match any outside offer. 


\subsection{The probability of the inventor willing to leave}

The incentives of the worker to leave is a more futile process (Lee and Mitchell, 1994), where many personal circumstances may be at play. For instance, according to the familiar situation of the worker, he will consider a firm change that involves a geographical move. Therefore, we should take into account personal data such as age, marital status or having children.

Apart from the personal characteristics, there are some standard facts that are likely to affect the willingness of the move. For instance, it has been extensively noted in the labor literature that as tenure increases, the chances of job change diminish drastically, mainly because people get established at their job (Hall,). We previously mentioned that tenure means more stock of knowledge and, therefore, a higher probability to receive an offer. However, we expect that the former effect dominate over the latter, because it is the inventor's willingness to change what finally determines whether he moves or he does not. The same argument applies for experience.

A highly relevant aspect of the researcher's work is the motivation. IBM offers a bunch of examples of inventors who left the company highly frustrated for the difficulty to pursue their creativity in a very rigid and bureaucratic organisation such as of IBM. These inventors went to work to direct IBM's competitors, such as Dell or HP or who established their own companies financed by firms such as Fujitsu. An inventor is specially frustrated when the firm shows no interest in his research interests and findings. This fact may play an important role in the moving decision of the inventor. In fact, this is one of the main reasons that motivate as well the creation of start-ups (Cassiman and Ueda, 2002). 


\section{Data}

I use patent data to track inventor's mobility. I use the USPTO patent database as compiled in the NBER Patent Citations Data File (Hall et al, 2001). I restrict my analysis to a sample of inventors working at some point of time at IBM as reflected by the affiliation of their patents. This sample consists of all the inventors whose surname begins with A-H, who sum up to 2394 inventors. These inventors file a total of 8924 patents during all their working life (at IBM and outside it) as identified with their patenting activity from 1970 to 1999 . I identified 713 moves. Movers represent a 33\% of the patents but only a $15 \%$ of the inventors (361). These moves include moves from other firms to IBM, from IBM to other firms or between other firms different from IBM. However, we restrict our analysis to the movement from IBM to outside firms. This type of moves represents 328 moves and affects to a $27 \%$ of the patents and $12 \%$ of the inventors (i.e. 280).

We have to be aware that tracking mobility through patent data has a set of limitations that we have to be aware of. The most important is that we can only identify a change if the inventor patents before as well as after the firm change. Covenants not to compete may play an important role in the non-patenting behavior of the inventor after the move. Another issue is the truncation of the patenting lives of these inventors: we do not know neither whether they actually start patenting the first year we observe a patent by them in the dataset (left truncation) nor whether their last patents as observed in the sample lead thereafter to a move (right truncation). An important source of bias may be the identification of inventors, due to spelling errors. In order to minimize this source of errors, manual checking has been performed once the algorithms had been run.

We have as well to be aware that not always that we identify that the engineer is the inventor of a patent granted to a firm different from the last firm for which he patented reflects a change of affiliation. Apart from an actual change of employer, this fact could reflect either a research collaboration or alliance between the inventor's employer and 
another firm where the latter gets the patent rights over the research results. Alternatively, it could reflect a particular kind of job change, i.e. leaving the job in order to create a start-up. However, in both cases, the implications concerning the drivers of the move as far as our analysis is concerned are not so different from a true move. In such cases, the importance of the absorption and ability to transfer knowledge is a driver as important as (whenever not more important than) in true moves. Therefore, we do not believe that this fact may actually bias our results.

\section{Descriptive Analysis on the Hiring Firms}

\subsection{Who are they?}

What about the hiring firms? As mentioned in the previous section, the literature has not analyzed who are the hiring firms and what knowledge they seek from outside hires. We have a set of hiring firms that hire a random sample of inventors working at IBM. We have 247 different hiring firms that form 354 different pairs of hiring firm-year of the incorporation of the hire ${ }^{1}$. We have data for the previous years to the incorporation of the engineer hired from IBM for 200 firms and 300 pairs firm-year pairs.

In Figure 1 we report a summary of the characteristics of these firms regarding their patent activity. From this descriptive analysis, we can infer what kind of firms is seeking (or reaches) IBM's know-how. There is a $19 \%$ of firms without patent data previous to the year of the incorporation of the hire. This fact may reflect that they are start-ups or small firms that only began to patent after the hiring. The rest $81 \%$ of the firms have patenting activity but there are far from being big patent holders. This distribution reflects the whole patent portfolio previous to the move for each pair of firm $\&$ year. Near to an $80 \%$ of the hiring firms are concentrated in the smaller values of the portfolio (below the mean value). This fact suggests that the big majority of firms that seek knowledge from IBM are not big patent holders but rather startups or small firms with no strong research

\footnotetext{
${ }^{1}$ Only 172 of these firms (that represent 237 pairs) hire an engineer directly from IBM -the others contract engineers that worked for IBM but not immediately before-.
} 
oriented trajectories. The mean number of years of patenting activity is 20 years (the median is 18), suggesting that they are firms with a established research trajectory but not an intensive patent trajectory. Only a $10 \%$ of them could be considered startups (less than 4 years with patenting activity).

If we pay attention to the technological core of these firms, around a $65 \%$ of them have their core -previous to the incorporation of the IBM hire- in the category 2 or 4 , both associated with the electronics sector. However, the resting 35\% are firms with their core outside the electronics industry (note that it is not that they patent also outside the electronics but mainly there).

It is interesting to look at Figure 2 how the hiring firms are distributed among the core categories in function of their portfolio. The patent holders with a patent portfolio higher than the mean are concentrated in the electronics categories (subcategories $22 \& 46$ ), whereas the lower tail of the patent holders distribution is spread across all categories.

Therefore, it seems that firms hiring engineers from IBM are quite heterogeneous. The majority of them are small patent holders not just in the electronics sector but spread over all the technological space. Then, there are a few bigger patent holders from the electronics industry (the biggest patent holder in our sample has a mean of 533 patents/year mainly in semiconductor-related technologies).

If we restrict to the 5-year time span before the hiring from $\mathrm{IBM}^{2}$ (unreported results), we observe basically the same facts: hiring firms are heavily concentrated on the lowest part of the patent portfolio distribution, even though the variance is more reduced. Approximately a $67 \%$ of these firms have their core in the categories 2 and 4.

\footnotetext{
${ }^{2}$ Note, however, that with this reduced time-span, we have data only on 196 firm-year pairs.
} 


\subsection{Where do they want to apply the outside knowledge?}

We match the core of the inventor previous to the quit (the patent class or subcategory where the majority of his patents are granted to) with the core of the hiring firm. We find that the majority of hires do not work previously in the same classes that the hiring firm primarily works on (only around a $13 \%$ of the inventors patent previously to the same class and a $22 \%$ in the same technological subcategory as the hiring firm mainly does). As well, the majority of them are not hired to work on the firm's core classes afterwards: a $19 \%$ work in the core class, a $28 \%$ in the firm's core subcategory ${ }^{3}$. Therefore, it does not seem that they want to "improve" their core but they mainly want to explore existing or new areas of knowledge. Just another fact: an $83 \%$ of the inventors working at the IBM's core that move work then in non-core areas of the new firm.

The majority of the inventors that were patenting in a subcategory core to their future employer remain patenting "there" $(57 \%)$. However, the ones that after the move work in the core of the new firm, a $62 \%$ were not patenting in these same core categories before. Therefore, the majority of engineers who work on the core do not "move" in terms of patenting behavior but the ones that patent on the core have indeed "moved" from other areas.

We have to be careful in interpreting these results, since the "core" category is just a proxy of the major focus of the firm as its patenting behavior suggests. However, i) reducing the "core" to the "highest" subcategory can be too restrictive, ii) the primary classification of a patent -in which it is based the classification by categories- is not always the unique main area of applicability of this technology and iii) not necessarily the higher number of patents should mean higher activity in this area-some areas are more "patent intensive" than others-.

\footnotetext{
${ }^{3}$ Note that these percentages are not with respect to the total number of moves, but to the ones that we have patent data for the hiring firms in the previous 5 years, that represent a $83 \%$ of the moves from IBM.
} 
We tested also (unreported results) whether the hiring firms were citing the inventors that they will hire afterwards. Only one third of the inventors were cited by their future employer before the move. This evidence, joint with the movement mainly to non-core areas, suggest that the hiring firms want to get access to a knowledge from unexplored (by them) technological areas.

\subsection{What type of knowledge may they have to access to?}

We use data on the patents filed by the inventor previous to the move as a proxy for the type of knowledge the firm wants to get access to. We compare the characteristics of the patents by the movers before the move with respect the patents by no-movers (without controlling for individual effects, just all the characteristics of patents by movers vs. nomovers -remember that in both cases are IBM patents). Patent characteristics have been tested in the literature as proxies for characterizing the invention they protect (see a summary in Palomeras, 2003). We perform a probit analysis to test the differences across different patent dimensions between the patents by would-be-movers and non-movers. We have 8118 patents of which a $73 \%$ belong to the non-movers group and a $27 \%$ to the movers group.

Results are displayed in Table 1. Indeed, there are significant differences between the two groups of "knowledge stocks". Results point that inventions by movers are of higher scientific relevance or importance-they are more cited- than inventions by non-movers, fact that suggests their inventions are of higher economic value. As well, patents by would-be-movers rely more on past knowledge, i.e. their inventions are more cumulative as opposite to radical breakthroughs -they make more citations to the previous literature-. Moreover, the knowledge they rely upon is more spread across the technological space or interdisciplinary -more original-. Additionally, they build upon previous research of the firm less frequently than no-movers do -rate of self citations made- and the research stream they begin is as well less pursued afterwards inside the firm -rate of self citations received). Interestingly, they are the outcome of more reduced teams of engineers, fact that we suggest it might be interpreted as a signal that the knowledge they embody is 
scarce. Finally, the inventions by would-be-movers have a higher probability of belonging to the previous firm's core.

Our results suggest that hiring firms are likely to be looking for know-how associated with important, cumulative, original inventions, that fall in the core and that represent streams of research quite innovative inside the firm but that it is not particularly interested to follow.

\section{Econometric Model}

We use event history analysis to analyze the hazard rate (the rate in a particular moment in time) that an engineer changes employer during his/her research life (the risk period). We proxy the research life by the "patenting life" of the individual and his/her employer change as a change of affiliation of the inventor as reflected in the patent documents where he/she figures like an inventor. The hazard function takes the form:

$$
\lambda_{u}(t, Z)=\lambda\left(t, Z_{t-1}(t) \mid u, \beta\right)
$$

where $\lambda$ is the generic expression for the hazard rate at patenting time $t, \mathrm{Z}$ is the vector of time dependent explanatory variables, $\beta$ is the vector of parameters to be estimated and $u$ is a random variable, distributed independently of $Z$ and $t$, that incorporates unobserved heterogeneity to the model.

Because of the characteristics of patent data, we observe time in discrete periods that correspond to years. However, an individual is not at "risk period" in every consecutive year from his/her first patent onwards but the time intervals at risk "appear" (or at least we are able to observe it) only when he/she patents. Therefore, the particular "unit of time" that we consider is the time where he/she does actually patent, what we refer to as patenting time. However, we introduce measures that directly take into account real time units.

$\mathrm{Z}(\mathrm{t})$ captures the explanatory variables related to the characteristics of the inventor's know-how that we believe affect the hazard rate of changing employer. They are observed in the previous period since what influences the move is all the characteristics 
accumulated up to the patenting time where we observe the change-variables for which this is not the case, previous period observations avoid endogeneity problems-. Explanatory variables include the variables mentioned in Section 4 that proxy for the stock of accumulated knowledge of the inventor plus the variables that proxy for the characteristics of this knowledge.

We introduce as controls regional and time dummies. There is evidence on the differences between regions on the intensity - or even the existence- of labor market flows for engineers (Almeida \& Kogut, 1999). As they note, moreover, mainly of the mobility happens to be intra-regional. In our case, the mere fact of working at certain locations of IBM's research facilities may affect considerably the probability of receiving an offer as well as the probability of accepting it by the engineer -depending on the existence of an active labor market and the concentration of firms in the region that affects the likelihood that a job change implies or not a change of geographical location.

$u$ captures the impact of omitted variables, in particular the inventor's personal characteristics (i.e. education, age, gender, marital status, number of children), that are likely to affect the hazard rate but that we do not have available to include in the estimation. Age has been noted by the labor literature as a predictor of the probability of job change for the general labor population (Hall). However, Zucker et al (2002) included this and other personal characteristics of the researchers and none of them affected in a significant way the likelihood of move. These omitted variables are likely to capture as well the characteristics related with the particular offer -and possibly counteroffer- that the inventor receives (i.e. wage offered, firm's reputation, new colleagues, whether move implies change of location, challenges of new work).

In order to perform survival analysis with discrete time data, it can be used either a logistic model or a proportional hazard model. I use the former. In particular, I use a probit random effects. Each observation represents a patenting year, i.e. a year where the inventor patents (one or more patents). 


\section{Results}

Results of different specifications of the survival model are reported in Table 2.

The first specification reported include the variables that reflect the knowledge base of the inventor, both quantitatively and qualitatively. The model is overall significant, as well as the rho, that captures the proportion of the total error variance accounted for by the unobserved effects. All the variables are significant but the quantity of patents granted to the inventor and the core. The number of years patenting, i.e. experience has a positive effect on the likelihood of moving while tenure, the number of years patenting at the last firm, i.e. IBM, has an as predicted negative effect. The number of patents granted to the engineer as an IBM employee enters not significantly but with a negative sign (not robust -it changes across specifications, always non-significant-). The overall index for the quality of the patents filed with the previous employer is positive and significant, as expected. The number of inventors is significantly negative, as predicted, which suggests that the more co-authors, the less valuable the individual knowledge is considered by outside employers. The core enters with a positive sign, as predicted, but it is not significant. We introduce controls for the time of each patent, the region where it is granted (we use the postate of the address of the inventor as a proxy) and its technological category. Moreover, we control for the time of entry of the inventor to the sample (minyr). Apart from the sign on patents, all of the other results are robust to different specifications around this set of variables.

In specification 2, we introduce the square of the experience variable. This new variable turns to negative the effect of experience whereas the square term picks up the negative effect. This means that experience has a negative effect on the likelihood to move but only up to a certain point. Therefore, the more likely to move are either the younger scientists or the older ones. I tested as well for the introduction of the squared tenure and quality, variables we may suspect to have an (inverse-)U shaped effect on the likelihood. 
The squared tenure enters significantly only if the squared experience is dropped. The squared quality is not significant even when introduced alone.

The third specification that we report introduces cmade and originality, variables that reflect the characteristics of the inventions filed with the previous employer. Even though these variables were found to be significantly different between the mover and no-mover group in a patent basis comparison, they actually do not affect significantly the probability of move. In fact, the introduction of them turns the rho, the proportion of the error variance that accounts for the unobserved heterogeneity, to non-significant.

We introduce in specification 4 the percentage of selfcitations made as well as received. The introduction of these variables restricts the number of observations to 1643 , because the value of these variables is missing in a considerable portion of the data. However, I perform all of the previous specifications with this reduced set of observations and results are basically the same. Therefore, it does not seem that the reduction in the number of observations affects the results. Citations made to patents by the same firm affect negatively but non significantly the probability of moving. Citations received by patents from the same firm enter in a significantly negative way. These results support somewhat the idea that inventors working at research lines less developed inside the firm are more likely to move. However, we have to be careful with this interpretation. In particular, selfcitations received may suffer from endogeneity: if the inventor moves, the probability that the research stream where he was working on is continued may lower, fact that would make self citations coming from the same firm less likely as well. Note as well that the rho is neither significant in this specification.

If we just keep the selfcitations received, the results are basically the same (specification 5) but we face the same problems of a reduced dataset and the possible endogeneity of this variable. I also tested the inclusion of some would-be meaningful interactions but none of them improved the fit of the model. 
Therefore, the specification that best fits the data seems to be the second one. I find that the probability of move of an engineer from IBM to another firm is negatively affected by the years that he spent in the firm as well as in the sector, even though in the latter case, there is a squared positive effect. This suggests that the younger and the older scientists are the most likely to leave for another firm, whereas the more recent engineers at the firm are the most likely to leave. The cumulative quality of the patents while working by the previous employer affects positively the probability to move. This fact suggests that the hiring firms actually want to get access to this highly valuable knowhow. However, the productivity -in quantitative terms- of these inventors does not affect significantly the likelihood to quit the firm (the effect, if any, would be the opposite: the more productive are more likely to stay). The cumulative number of co-inventors the engineer has been working with affects negatively the probability of leaving. This fact could be interpreted in several ways: the higher the number of co-inventors, the more dispersed his knowledge is -the less unique- and, therefore, the less valuable for outside firms. Alternatively, the higher the number of co-inventors could point out that the inventor is actually involved in projects where the firm devotes resources and, therefore, he is "established" in the firm. Finally, the inventors that are more likely to leave are more likely to be working at the firm's core, even though not in a significant way.

\section{Conclusion}

In this paper, we examine the quits of engineers from the largest firm in the semiconductor sector, IBM to other firms. Our main finding is that the engineers with higher human capital as measured by their individual productivity in qualitative terms are the most likely to quit the firm. This observation has important implications in different directions. First of all, it implies that hiring external engineers is a learning mechanism restricted to capture high-quality know-how and, therefore, that the knowledge flow generated through mobility is basically of this type. At the same time, it may suggest that such knowledge is the most difficult to codify and that its correct use needs from the interpretation of its creator. Second, it suggests that high-quality engineers are the most willing to leave the firm, confirming the importance of the motivation for highly creative 
researchers -a firm change may be a challenge that impulse them to pursue their innovative activities-. However, descriptive results unreported here suggest that after the firm change, these inventors become more productive in quantitative, not in qualitative, terms. Third, this result has implications for the human resources policy at innovative firms in order to prevent the quit of their best researchers or, alternatively, to manage the research teams in order to minimize the impact of these quits.

The results of this paper are a first step in a better understanding of the determinants and consequences of the knowledge flows generated by the mobility of engineers between firms. A challenging topic with a lot of questions still unanswered.

\section{References}

Agrawal, A.K., Cockburn, I.M., McHale, J., 2003. "Gone but Not Forgotten: Labor Flows, Knowledge Spillovers and Enduring Social Capital", NBER WP 9950 , September.

Almeida, P., Kogut, B., 1999. "Localization of Knowledge and the Mobility of Engineers in Regional Networks”, Management Science, Vol.45, No.7, July, 905-917.

Boeker, W., 1997. "Executive Migration and Strategic Change: The Effect of Top Manager Movement on Product Entry", Administrative Science Quarterly, Vol. 45, 766-801.

Cassiman, B., Ueda, M., 2002. “Optimal Project Rejection and New Firm Start-ups”, CEPR, WP 3429

Carroll, P., 1994. "Big Blues: The Unmaking of IBM”, Crown Publishers, New York.

Ettlie, J.E., 1985. "The Impact of Interorganizational manpower flows on the innovation process". Management Science, Vol.31, 1055-1071

Hall, B.H., Jaffe, A., Trajtenberg, M., 2001. “The NBER Patent Citations Data File: Lessons, Insights and Methodological Tools", NBER

Harhoff, D., Narin, F., Scherer, F., Vopel, K., 1999. "Citation Frequency and the Value of Patented Inventions", The Review of Economics and Statistics, 81(3):511-515

Geroski, 1995. "Do Spilovers Undermine the Incentive to Innovate?" S. Dowrick editors, Economic Approaches to Innovation, Edwar Elgar, Aldershot, UK, 76-97.

Gilfillan, S.C., 1935. “The Sociology of Invention”. Follett Publishing Co., Chicago.

Hanson, D., 1982. "The New Alchemists: Silicon Valley and the Microelectronics Revolution" Little, Brown and Company, Boston. 
Jaffe, A.B., Trajtenberg, M., Henderson, R., 1993 "Geographic Localization of Knowledge Spillovers as Evidenced by Patent Citations", Quarterly Journal of Economics, Vol. 108, 577-598.

Lee, T.W., Mitchell, T.R., 1994. "An Alternative Approach: The Unfolding model of voluntary employee turnover" Academy of Management Review, Vol. 19, 51-89.

Malecki, E.J., 1991. “Technology and Economic Development”. John Wiley and Sons, New York.

Moen, J., 2000. "Is Mobility of Technical Personnel a Source of R\&D Spillovers?” NBER WP 7834, August

Mowery, D.C., Oxley, J.E., Silverman, B.S., 1998. "Technological Overlap and Interfirm Coordination: Implications for the Resource-Based View of the Firm" Research Policy, Vol. 27, 507-523.

Palomeras, N., 2003. “"Waking Up Sleeping Markets for Technology”, UPF, mimeo.

Rosenkopf, L. , Almeida, P., 2003. "Overcoming Local Search Through Alliances and Mobility", Management Science, Vol.49, No.6, June, 751-766.

Saxenian, A., 1990. "Regional Networks and the Resurgennce of Silicon Valley". California Management Review, Vol. 33 (1), 89-112.

Shane, S., 2001. "Technological Opportunities and New Firm Creation" Management Science, Vol.47, No.2., 205-220

Song, J., Almeida, P. and Wu, G., 2003. "Learning-by-Hiring: When Is Mobility More Likely to Facilitate Interfirm Knowledge Transfer?”, Management Science, Vol. 49, No.4, 351-365

Zucker, L.G., Darby, M.R., Torero, M., 2002. “Labor Mobility from Academe to Commerce”. Journal of Labor Economics, Vol.20, no. 3, 629-660.

Yamaguchi, K., 1991. "Event History Analysis”. London Sage. 


\section{Appendix}

Figure 1. Distribution of the patent portfolio of the hiring firms.

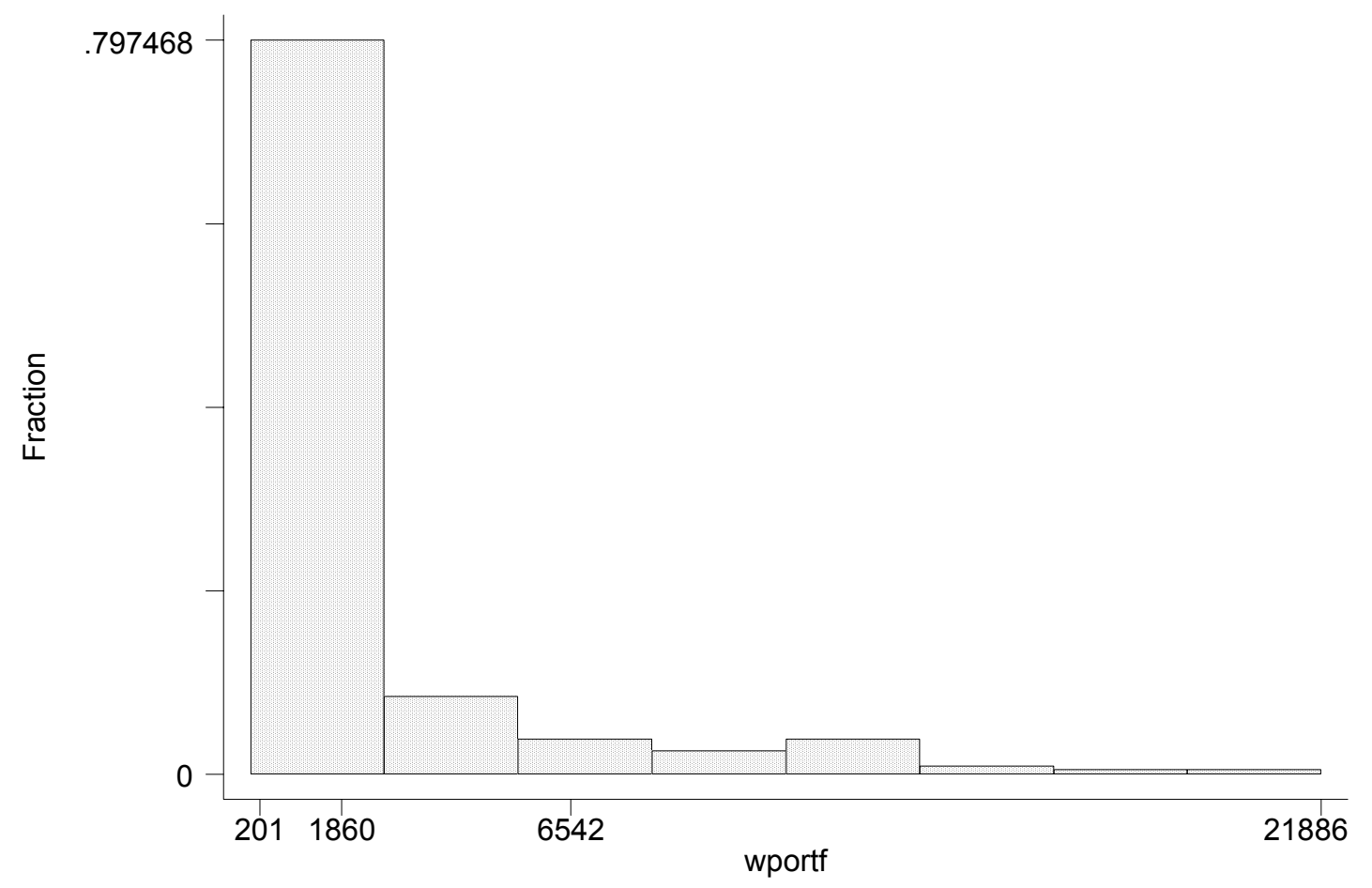


Figure 2. Distribution of Portfolio by Subcategories.

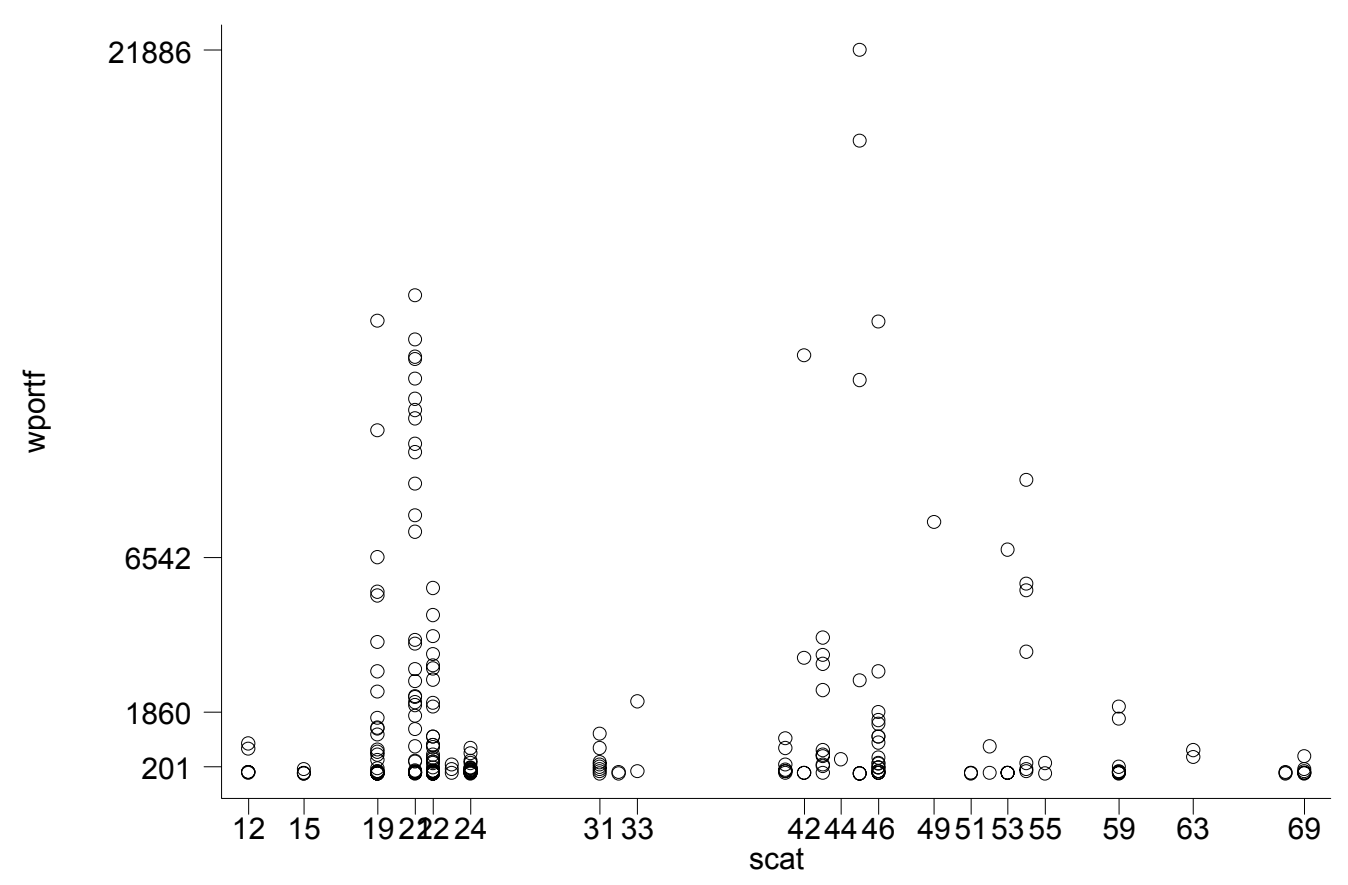


Table 1. Probit estimates. Characteristics of the inventions by movers. Dependent variable: mover/non-mover inventor .

\begin{tabular}{|c|c|}
\hline Variable & Coefficient \\
\hline $\begin{array}{l}\text { Generic } \\
\text { Claims }\end{array}$ & $\begin{array}{l}.0393994 \\
(.03354)\end{array}$ \\
\hline $\begin{array}{l}\text { Cumulativeness } \\
\text { Citations made }\end{array}$ & $\begin{array}{l}.2029423 * * * \\
(.0441029) \\
\end{array}$ \\
\hline $\begin{array}{l}\text { Quality } \\
\quad \text { Citations received }\end{array}$ & $\begin{array}{l}.2733358^{* * *} \\
(.0526353)\end{array}$ \\
\hline $\begin{array}{l}\text { Interdisciplinarity } \\
\text { Original }\end{array}$ & $\begin{array}{l}-.238859 * \\
(.1260977) \\
\end{array}$ \\
\hline $\begin{array}{l}\text { Scope } \\
\text { General }\end{array}$ & $\begin{array}{l}-.1725249 \\
(.125731)\end{array}$ \\
\hline $\begin{array}{l}\text { Uniqueness } \\
\text { Coinventors }\end{array}$ & $\begin{array}{l}-.3233739^{* * *} \\
(.0534547) \\
\end{array}$ \\
\hline $\begin{array}{l}\text { Technological Fit } \\
\text { Core }\end{array}$ & $\begin{array}{l}.1401482^{* * *} \\
(.0535714)\end{array}$ \\
\hline $\begin{array}{l}\text { Project's fit } \\
\text { Selfcitations made }\end{array}$ & $\begin{array}{l}-.2637926 * * * \\
(.0344203)\end{array}$ \\
\hline Selfcitations received & $\begin{array}{l}-.4364955^{* * * *} \\
(.0743224)\end{array}$ \\
\hline Time of patent & Included \\
\hline Technological category & Included \\
\hline Number of obs & 4126 \\
\hline LR chi2(19) & $254.16^{* * *}$ \\
\hline Pseudo R2 & 0.0546 \\
\hline
\end{tabular}


Table 2. Probit Random Effects on the Probability of Firm Quit.

Marginal effects at the Median.

\begin{tabular}{|c|c|c|c|c|c|}
\hline & Specific. 1 & Specific. 2 & Specific. 3 & Specific. 4 & Specific. 5 \\
\hline Experience & $\begin{array}{l}.3179 * * * \\
(.099)\end{array}$ & $\begin{array}{l}-2.0307 * * * \\
(.636)\end{array}$ & $\begin{array}{l}-1.978 * * * \\
(.637)\end{array}$ & $\begin{array}{l}-1.881 * * * \\
(.595)\end{array}$ & $\begin{array}{l}-3.174 * * * \\
(.875)\end{array}$ \\
\hline Experience squ & & $\begin{array}{l}.8713 * * * \\
(.232)\end{array}$ & $\begin{array}{l}.8701 * * * \\
(.232)\end{array}$ & $\begin{array}{l}.8555 * * * \\
(.218)\end{array}$ & $\begin{array}{l}1.296^{* * * *} \\
(.323)\end{array}$ \\
\hline Tenure & $\begin{array}{l}-.2995^{* * *} \\
(.111)\end{array}$ & $\begin{array}{l}-.3703 \\
(.108)\end{array}$ & $\begin{array}{l}-.3776^{* * *} \\
(.107)\end{array}$ & $\begin{array}{l}-.5119 * * * \\
(.088)\end{array}$ & $\begin{array}{l}-.3957 * * * \\
(.143)\end{array}$ \\
\hline Patents & $\begin{array}{l}-.3229 * * * \\
(.117)\end{array}$ & $\begin{array}{l}-.3216^{* * * *} \\
(.113)\end{array}$ & $\begin{array}{l}-.0693 \\
(.649)\end{array}$ & $\begin{array}{l}.0042 \\
(.168)\end{array}$ & $\begin{array}{l}-.1952 \\
(.307)\end{array}$ \\
\hline Quality & $\begin{array}{l}.0815 \\
(0.176)\end{array}$ & $\begin{array}{l}.0681 \\
(.057)\end{array}$ & $\begin{array}{l}.0952 * \\
(.058)\end{array}$ & $\begin{array}{l}.0716 \\
(.051)\end{array}$ & $\begin{array}{l}.3279 * * * \\
(.097)\end{array}$ \\
\hline Coinventors & & & $\begin{array}{l}-.2404 * * * \\
(.094)\end{array}$ & $\begin{array}{l}-.2117 * * * \\
(.083)\end{array}$ & $\begin{array}{l}-.2158 * * \\
(.107)\end{array}$ \\
\hline Core & & & $\begin{array}{l}.0494 \\
(.137)\end{array}$ & $\begin{array}{l}.0396 \\
(.123)\end{array}$ & $\begin{array}{l}.2342 \\
(.170)\end{array}$ \\
\hline Cmade & & & & $\begin{array}{l}.0432 \\
(.069)\end{array}$ & $\begin{array}{l}.0074 \\
(.080)\end{array}$ \\
\hline $\begin{array}{l}\text { Selfcitations } \\
\text { received }\end{array}$ & & & & & $\begin{array}{l}-.3495^{* * *} \\
(.128)\end{array}$ \\
\hline $\begin{array}{l}\text { Selfcitations } \\
\text { cmade }\end{array}$ & & & & & $\begin{array}{l}-.1540 \\
(.111)\end{array}$ \\
\hline Entry time & $\begin{array}{l}-.0288^{* * *} \\
(.010)\end{array}$ & & $\begin{array}{l}-.0387 * * * \\
(.011)\end{array}$ & $\begin{array}{l}-.0335^{* * *} \\
(.010)\end{array}$ & $\begin{array}{l}-.0349 * * * \\
(.012)\end{array}$ \\
\hline Patent time & Included & Included & Included & Included & Included \\
\hline Year & Included & Included & Included & Included & Included \\
\hline $\begin{array}{l}\text { Technological } \\
\text { category }\end{array}$ & Included & Included & Included & Included & Included \\
\hline $\begin{array}{l}\text { Number of } \\
\text { observations }\end{array}$ & 3219 & & 3218 & 3046 & 1643 \\
\hline Number of gro & 1279 & & 1278 & 1256 & 988 \\
\hline Wald chi2 & $103.16^{* * *}$ & & 130.37 & 164.70 & 111.05 \\
\hline rho & $\begin{array}{l}.2469 * * * \\
(.091)\end{array}$ & & $\begin{array}{l}.1858 * * * \\
(.090)\end{array}$ & $8.32 \mathrm{e}-07$ & $8.32 \mathrm{e}-07$ \\
\hline
\end{tabular}

